\title{
Characterization of Tropical Starches Modified with Potassium Permanganate and Lactic Acid
}

\author{
Fabiano Franco Takizawa, Graziela de Oliveira da Silva, Francisco Eneias Konkel and Ivo \\ Mottin Demiate* \\ Universidade Estadual de Ponta Grossa; Departamento de Engenharia de Alimentos; Av. General Carlos \\ Cavalcanti, 4748; Campus de Uvaranas; 84030-900; demiate@interponta.com.br; Ponta Grossa - PR - Brazil
}

\begin{abstract}
In the present work some tropical starches were modified by an oxidative chemical treatment with potassium permanganate and lactic acid. The native and modified samples were evaluated by mid-infrared spectroscopy, differential dyeing, $\mathrm{pH}$, expansion power, solubility and swelling power, clarity of the pastes, susceptibility to syneresis, carboxyl content and reducing power. All modified samples presented dark blue color, higher expansion power (except corn starch), carboxyl content and reducing power. The solubility of the modified starch granules was very high at $90^{\circ} \mathrm{C}$. At this temperature, it was not possible to measure their swelling power. The viscographic analysis showed decrease in peak viscosity and higher degree of cooking instability. The principal component analysis of the mid-infrared spectra allowed separation between native and modified samples due to the presence of carboxyl groups. The expansion was inversely related with amylose content of the starches.
\end{abstract}

Key words: Tropical starches; oxidized starches; FTIR

\section{INTRODUCTION}

Starch, the main reserve carbohydrate of several crops, is highly abundant in nature and can be easily extracted with high purity and low cost (Cereda et al., 2001). Industry is using starch for a long time as an ingredient in foods, especially for its functional properties. Depending on the source, the starches have different applications, improving consistency, stability, and other properties (Smith, 1982). The most common plant sources for food starches used all over the world are corn, wheat, potato and cassava. However, there is a constant search for new starches presenting different properties due to the continuous need of improving quality of products and processes as well as development of new products. Chemical modifications of native starches which gives distinct functional properties have been developed due to the desire of the industries in bringing new products to the market and improving others. All starches, native and modified, have structural differences and a great number of studies are being done to show each particularity. The technological development and the evolution on food industry process show up high tendency for modifications that preserve desirable natural characteristics. The degree of modification of starches produced under controlled temperature and $\mathrm{pH}$ affects directly their price and applications. However, it is necessary to understand how different starches answer to these modifications for an industrial classification and control (Dolmatova et al., 1998).

*Author for correspondence 
Hoover (2001), in a review about tropical starches, discussing the granule morphology, chemical composition and proximate analysis, cristalinity, structure of amylose and amylopectin, swelling power and solubility, gelatinization, rheology, retrogradation and digestibility concluded that there was a lack of information on the surface properties, granule cristalinity, double helical content, amylose chain length, chain length distribution of amylopectin, and physical properties (digestibility, retrogradation and rheology) of tuber and root starches. He reported that except for few crops such as potato, the available data refer to few cultivars and were obtained by different methods, not allowing comparisons. Moorthy (1994) found that the examination of the properties of the different tuber starches revealed a wide variability in their properties, which was not found in cereal starches. Oxidized starches are widely used in paper, textile and food industries. In food applications, the preparations of oxidized starches are obtained as thickeners and subsidiary gelatin agents, in sauces, jellies, puddings and ice creams (Boruch, 1985). Although these starches are being used since many decades, their structural changes and the mechanisms of reaction are still not well understood, mainly when considering low levels of oxidants (Wang and Wang, 2003). The oxidative treatment affects the starch viscosity and the paste stability (Forssell et al., 1995). It is well known that there is a decrease in the starch molecular weight that allows its addition in high quantities without raising excessively the paste or gel viscosity (Autio et al., 1996).

Demiate and Cereda (2000) studied some physicochemical characteristics of cassava starches modified by a chemical treatment with potassium permanganate and lactic acid. The chemical treatment was made in order to produce starch with baking property (Demiate et al., 2000) or expansion power. The authors succeeded in producing chemically modified samples presenting the expansion power, what was known only for cassava sour starch. This was the first time that a chemically modified starch was evaluated for such a property and the aim of the research was to develop a new product for food use. Considering that the reagents employed are not the same described for conventional modifications, it will be necessary to investigate alternative chemicals for producing food grade modified starches.
The objective of this paper was to produce modified starches from selected tropical sources by the same treatment described above and to evaluate their properties.

\section{MATERIALS AND METHODS}

\section{Materials}

Cassava (Manihot esculenta), corn (Zea mays), waxy corn (Zea mays) and potato (Solanum tuberosum) starches were obtained from Brazilian producers. Starches not available on market were extracted in the laboratory. Peruvian carrot (Arracacia xanthorrhiza) and sweet potato (Ipomoea batatas) roots were washed, peeled, crushed and the starch extracted by washing and sieving. In the first washing of the crushed roots, a 200ppm metabisulfite solution was used to control enzymatic browning. The starches were dried in an air oven at $45^{\circ} \mathrm{C}$ for 24 hours. The tuberous starches were selected due to their technological importance (potato and cassava) or potential (Peruvian carrot and sweet potato). Corn and waxy corn were included for comparison considering their commercial importance.

\section{Modification by Oxidative Treatment}

The samples were submitted to an oxidative treatment as described by Demiate (1999). The starches $(20 \% \mathrm{w} / \mathrm{w})$ were first treated with potassium permanganate $0.1 \mathrm{~N}$ for 30 minutes under agitation at room temperature $\left(c a \cdot 20^{\circ} \mathrm{C}\right)$. The oxidized samples were filtered (Whatman $n^{\circ}$ 2) and then washed with deionized water to remove the excess of reagent. The washed starch was treated with a $1 \% \mathrm{w} / \mathrm{w}$ lactic acid solution $(20 \% \mathrm{w} / \mathrm{w}$ of starch and final mass of $1 \mathrm{~kg}$ ) for one hour at room temperature and then recovered by the same procedure. The samples were washed with deionized water to eliminate all the soluble components, dried in air oven at $50^{\circ} \mathrm{C}$ for 24 hours and then stored in hermetic flasks.

\section{pH determination}

The $\mathrm{pH}$ was analyzed in a suspension of starch $(20 \mathrm{~g})$ in deionized water $(100 \mathrm{~mL})$ after agitation for 30 minutes, employing a digital $\mathrm{pH}$ potentiometer (Hanna Instruments, mod. HI 8424, Woonsocket RI, USA) with a DME - CV1 combined electrode (Digimed, São Paulo, Brasil). 


\section{Reducing power}

The reducing power was measured as the reduction of ferric to ferrous cyanide by the starch, with generation of a precipitate. The ferric ions in excess reduce iodine which was titrated with thiosulphate (International Starch Institute, 2001).

\section{Carboxyl content}

The content of carboxyl was determined by suspension of $500 \mathrm{mg}$ of starch in $30 \mathrm{~mL} 0.1 \mathrm{~N}$ $\mathrm{HCl}$; after 30 minutes these samples were washed with de-ionized water, and then suspended in 300 $\mathrm{mL}$ de-ionized water and heated at boiling temperature under agitation for 10 minutes. Hot solution was titrated with $0.002 \mathrm{~N} \mathrm{NaOH}$, using phenolphthalein as indicator. Carboxyl content was expressed as \% $\mathrm{COOH}(\mathrm{w} / \mathrm{w})$.

\section{Differential dyeing}

The samples $(1 \mathrm{~g})$ were suspended in $25 \mathrm{~mL}$ of $0.1 \%$ methylene blue under agitation for 30 minutes, washed with deionized water and filtered. The samples were dried in air oven at $50^{\circ} \mathrm{C}$.

\section{Solubility and swelling power}

These properties were evaluated at different temperatures $\left(50,60,80\right.$ and $\left.90^{\circ} \mathrm{C}\right)$, as described by Leach et al. (1959). The analysis was carried out in $50 \mathrm{~mL}$ leak proof centrifuge tubes, by taking a suspension of starch in deionized water in water bath under agitation at the selected temperatures. After 30 minutes, the samples were centrifuged $(3,400 \mathrm{rpm} / 15$ minutes $)$, separating the supernatant, which was collected and dried for soluble fraction quantification. The pellets, containing the swollen starch granules, were weighed. The ratio between the final mass and the initial dry matter was considered the swelling power. The solubility was expressed in weight percentage and the swelling power in weight increase.

\section{Viscographic analysis}

Hot paste behavior was analyzed with a Rapid Visco Analyser (Newport Scientific, Narabeen, Australia) (Garcia, 1996). Samples (2 g d.m.) were suspended in $28 \mathrm{~g}$ of solvent by utilizing an Ultraturrax T25 (Ika, Staufen, Germany), as described by Mestres and Rouau (1997). Deionized water was employed as solvent. The RVA temperature program was as follows: maintaining at $35^{\circ} \mathrm{C}$ for two minutes, heating to $95^{\circ} \mathrm{C}$ for five minutes and cooling until $50^{\circ} \mathrm{C}$ at $6^{\circ} \mathrm{C} /$ minute rate. Cooking profile of the samples was evaluated by considering the viscosity peaks, pasting temperature and final viscosity at $50^{\circ} \mathrm{C}$.

\section{Clarity of the starch paste}

The samples were suspended in deionized water and gelatinized. The paste clarity was observed immediately after cooking (hot condition) and after cooling at room temperature (cold condition). Petry dishes containing starch paste were photographed against a black and white background to help visual observation of the paste transparence or opacity (Cereda and Wosiacki, 1985).

\section{Mid-infrared spectroscopy}

The samples were analyzed using a Nicolet Avatar 360 spectrophotometer (Thermo Nicolet, Madison WI, USA) with deuterated triglycine sulfate (DTGS) detector. The spectral range considered was 4000 to $700 \mathrm{~cm}^{-1}$, which allowed a complete investigation of the molecular structure (Dupuy et al., 1997; Dupuy, 1993). KBr (150 mg) and sample (2 mg in dry base) pellets were obtained in hydraulic press (10 ton). The average spectra were explored by multivariate analysis. The number of scannings was 100 and the triangular apodization function of the standard Nicolet software used for the collection of the spectra (Dupuy et al., 1997; Dupuy, 1993).

The average spectra were converted to numeric files and then explored by principal component analysis (PCA), considering the spectral range from $1589-1620$ and $1714-1778 \mathrm{~cm}^{-1}$ to verify the influence of the modification. The software "The Unscrambler" (The Unscrambler, 1997) was employed for studying the spectral information.

\section{Expansion power}

This property was evaluated by partial gelatinization of $12 \mathrm{~g}$ of starch with $10 \mathrm{~mL}$ boiling water with production of a dough. Dough was divided in three balls of approximately same size. These balls were baked at $200^{\circ} \mathrm{C}$ for 20 minutes, and after cooling at room temperature, weighed. Their volumes, after covering with a paraffin layer, were measured by total submersion in water, in a graduated cylinder. Expansion was registered as specific volume, in $\mathrm{mL} \cdot \mathrm{g}^{-1}$ (Demiate et al., 2000).

\section{Syneresis}

Starch suspension at $8 \%(\mathrm{w} / \mathrm{w})$ in deionized water was gelatinized and kept at boiling temperature 
and agitation for 10 minutes. The gel was poured on a standardized plastic cup and stored in freezer $\left(-18^{\circ} \mathrm{C}\right.$ for $\left.24 \mathrm{~h}\right)$. When the gel was cold after thawing $\left(2 \mathrm{~h}\right.$ at $\left.40^{\circ} \mathrm{C}\right)$, it was detached from the cup and the weight of water loss measured. The amount of free water was expressed as percentage of weight loss and two cycles of freeze-thawing were considered. All the samples, from the first and second cycles, were frozen $\left(-18^{\circ} \mathrm{C}\right.$ for $\left.24 \mathrm{~h}\right)$ and thawed $\left(40^{\circ} \mathrm{C}\right.$ for $\left.2 \mathrm{~h}\right)$ together at the same conditions. For the second cycle, the cups containing the starch pastes were only thawed but the paste was kept inside the cup. After complete thawing, the cups were taken back to the freezer for more $24 \mathrm{~h}$ and then thawed again at $40^{\circ} \mathrm{C}$ for $2 \mathrm{~h}$ and the freed water weighed.

\section{RESULTS AND DISCUSSION}

The selected tropical starches present different physico-chemical characteristics, what can be exemplified by their amylose contents, shown in Table 1.

Table 1 - Amylose content of selected starches.

\begin{tabular}{lc}
\hline Source & Amylose \% \\
\hline Potato & $25.4^{1}$ \\
Sweet potato & $19.1^{1}$ \\
Peruvian carrot & $23.0^{2}$ \\
Corn & $24.5^{3}$ \\
Waxy corn & $1.1^{3}$ \\
Cassava & $18.6^{1}$ \\
\hline
\end{tabular}

${ }^{\mathrm{T}}$ Hoover (2001); ${ }^{2}$ Leonel and Cereda (2002); ${ }^{3}$ Zheng and Sosulski (1998).

Table 2 - pH, carboxyl content (COOH), reducing power (R.P) and expansion power (E.P.) of the samples.

\begin{tabular}{|c|c|c|c|c|}
\hline Samples & pH & $\begin{array}{c}\text { COOH } \\
\% \mathrm{w} / \mathrm{w}\end{array}$ & $\begin{array}{c}\text { R.P. } \\
\text { mgCu.g }\end{array}$ & $\begin{array}{c}\text { E.P. } \\
\mathrm{mL} \cdot \mathrm{g}^{-1}\end{array}$ \\
\hline \multicolumn{5}{|c|}{ Native starches } \\
\hline Peruvian carrot & 5.3 & 0.25 & 5.2 & 2.5 \\
\hline Cassava & 5.9 & 0.16 & 2.7 & 2.2 \\
\hline Corn & 4.9 & 0.23 & 2.9 & 1.3 \\
\hline Potato & 5.8 & 0.27 & 0.0 & 3.1 \\
\hline Sweet potato & 5.7 & 0.23 & 2.8 & 2.4 \\
\hline Waxy corn & 5.0 & 0.16 & 8.5 & 8.5 \\
\hline \multicolumn{5}{|c|}{ Modified starches } \\
\hline Peruvian carrot & 4.5 & 0.31 & 26.2 & 7.1 \\
\hline Cassava & 4.7 & 0.42 & 38.9 & 11.3 \\
\hline Corn & 5.7 & 0.32 & 35.9 & 1.2 \\
\hline Potato & 4.0 & 0.42 & 28.0 & 4.6 \\
\hline Sweet potato & 4.8 & 0.35 & 26.4 & 8.2 \\
\hline Waxy corn & 6.2 & 0.29 & 38.1 & 19.4 \\
\hline
\end{tabular}

The amylose content certainly has great interference on the results. The waxy corn showed a very low level and was studied in order to verify this kind of interference. In case of sweet potato, the yield of starch extraction was of $21.5 \%$ (wet basis) and starch purity was $99.4 \%$ (dry basis) (Silva et al., 2002).

\section{pH determination}

The lowest values for native samples were detected for corn and waxy corn (4.9 and 5.0 respectively) that were commercial starches extracted in a different manner from the other starches. These cereal starches, after modification, presented the highest $\mathrm{pH}$ values (5.7 and 6.2 respectively). There was an indication of different behavior between the cereal and tuberous starches studied. Results of $\mathrm{pH}$ are shown in Table 2. 


\section{Reducing power}

As shown in Table 2, the modified samples had higher reducing power than the native samples. Glucose polymers were fragmented by the oxidative treatment, decreasing the molecular weight and exposing a higher number of reducing endings that were easily oxidized to carboxylic acids. The depolymerization was confirmed by Demiate and Cereda (2000) who detected decrease of intrinsic viscosity for cassava starch modified by the chemical treatment with potassium permanganate and lactic acid.

\section{Carboxyl content}

The results obtained by carboxyl quantification showed that the modified samples had higher content than native samples (Table 2). The increasing of the carboxyl content after the oxidative treatment has been discussed by different researchers (Ali and Kempf, 1986; Wang and Wang, 2003; Zhu et al., 1998). The carboxyl content of different starches varied also as found in the literature (Kuakpetoon and Wang, 2001). The high carboxyl content of the modified starches could be directly related with the molecular fragmentation due to the oxidative treatment.

Native potato starch showed the higher carboxyl content when compared to the other samples.

Kuakpetoon and Wang, 2001 also found that potato starch had higher carboxyl content when compared to corn and rice starches but using sodium hypochlorite for the oxidative treatment.

\section{Solubility and swelling power}

The swelling power and solubility of starch granules showed a great evidence of interaction on the starch chains between the amorphous and crystalline regions. When starch is submitted to heating in excess of water, there is a relaxation of the crystalline structure and the groups of amylose and amylopectin associate with water molecules through hydrogen bondings. This causes an increase in the swelling power and in the solubility of the granules (Hoover, 2001).The swelling power increased with the increase of temperature. According to Hashim et al, 1992, during the gelatinization temperature the starch granule has a limited swelling in which only a small amount of carbohydrate is solubilized but at $90^{\circ} \mathrm{C}$ there is an increase in the swelling power and a large amount of carbohydrate leaks from the granular structure. The results of swelling power for modified samples were lower than for native ones; probably this fact was due to the oxidative treatment, which turned the granules weaker and easier to be disrupted. That could be easily exemplified by the swelling of the native and modified potato starch. The native potato starch showed higher swelling power when compared with the other samples, despite the fact that the value $\left(100\right.$ times at $\left.90^{\circ} \mathrm{C}\right)$ was much lower than that found in the literature (1159 times at $90^{\circ} \mathrm{C}$ ) (Leach, 1959) and it is probably due to the presence of phosphate groups (Galliard and Bowler, 1987).

The solubility increased with the increasing of the temperature as mentioned by Paterson et al., 1994. Due to the fact that the oxidized starch pastes presented high transparency, there was an additional difficulty in identifying the separation of the two phases after centrifugation and as a consequence some of the results were lost .

\section{Differential dyeing}

The samples submitted to the methylene blue differential dyeing showed the expected results. The native starches presented a lighter blue color when compared to the modified starches, except the native potato starch that showed a dark blue color; this fact should be associated to the presence of phosphate groups. This different adsorption of methylene blue is due to the presence of carboxyl groups in modified starches. The anionic carboxyl, which is present in modified starches, has a higher affinity to methylene blue that is cationic.

\section{Viscographic analysis}

Generally the pasting temperatures of the modified starches were lower than that of the native. The starches from Peruvian carrot, potato and cassava presented pasting temperatures $\left(\mathrm{ca} .70^{\circ} \mathrm{C}\right)$ lower than that of regular corn starch $\left(\mathrm{ca} .80^{\circ} \mathrm{C}\right)$; the literature indicates that starches from tuberous roots have lower pasting temperatures than cereal starches (Thomas and Atwell, 1999). The modified starches presented lower peak viscosity and higher cooking instability (Figure 1). The peak viscosity represented the highest level of completely swollen granules (Thomas and Atwell, 1999). There are some evidences that the granule swelling is limited by amylose; though, waxy starches have the highest swelling power while amylose rich starches present limited swelling (Lii et al, 1995; Tester and Morrison, 1990). 
Table 3 - Swelling power, solubility and paste clarity of the samples.

\begin{tabular}{|c|c|c|c|c|c|c|c|c|c|c|}
\hline & \multicolumn{4}{|c|}{ Swelling power (times) } & \multicolumn{4}{|c|}{ Solubility } & \multicolumn{2}{|c|}{ Paste clarity } \\
\hline & $50^{\circ} \mathrm{C}$ & $60^{\circ} \mathrm{C}$ & $80^{\circ} \mathrm{C}$ & $90^{\circ} \mathrm{C}$ & $50^{\circ} \mathrm{C}$ & $60^{\circ} \mathrm{C}$ & $80^{\circ} \mathrm{C}$ & $90^{\circ} \mathrm{C}$ & Hot & Cold \\
\hline \multicolumn{11}{|c|}{ Native starches } \\
\hline Peruvian carrot & 5.4 & 17.6 & 31.2 & 39.4 & - & 4.0 & 11.9 & 19.6 & TL & TL \\
\hline Cassava & - & 18.8 & 23.2 & 34.9 & - & 4.4 & 18.4 & 21.5 & $\mathrm{OP}$ & TR \\
\hline Corn & 2.2 & 2.9 & 11.9 & 15.3 & 0.8 & - & 8.2 & 8.6 & $\mathrm{OP}$ & $\mathrm{OP}$ \\
\hline Potato & 3.0 & 18.0 & 36.5 & 100.0 & 0.4 & 3.9 & 9.5 & n.a. & $\mathrm{OP}$ & $\mathrm{OP}$ \\
\hline Sweet potato & 3.1 & 2.5 & 22.6 & 21.9 & 0.6 & - & 8.8 & 10.0 & $\mathrm{OP}$ & $\mathrm{OP}$ \\
\hline Waxy corn & 3.5 & 3.4 & 38.7 & 65.4 & 0.3 & - & 7.1 & 15.3 & $\mathrm{OP}$ & $\mathrm{OP}$ \\
\hline \multicolumn{11}{|c|}{ Modified starches } \\
\hline Peruvian carrot & 3.6 & 15.9 & $(*)$ & $(*)$ & 5.9 & 22.9 & $(*)$ & $(*)$ & TR & TR \\
\hline Cassava & 3.1 & 2.7 & $(*)$ & $(*)$ & 1.0 & 13.2 & $(*)$ & $(*)$ & TR & TR \\
\hline Corn & 3.1 & 7.9 & 13.7 & 10.0 & 1.4 & 3.2 & 48.0 & 79.3 & TL & TL \\
\hline Potato & 3.2 & 22.0 & 5.3 & $(*)$ & 0.2 & 13.2 & $(*)$ & $(*)$ & $\mathrm{TL}$ & TR \\
\hline Sweet potato & 3.1 & 2.5 & $(*)$ & $(*)$ & 1.1 & 1.0 & $(*)$ & $(*)$ & TR & TR \\
\hline Waxy corn & 3.1 & 3.3 & $(*)$ & $(*)$ & 4.1 & 8.0 & $(*)$ & $(*)$ & TL & TR \\
\hline
\end{tabular}

(*) no results; - not detected; n.a. not analyzed; $\mathrm{OP}=$ opaque; TR = translucent; TR = transparent.
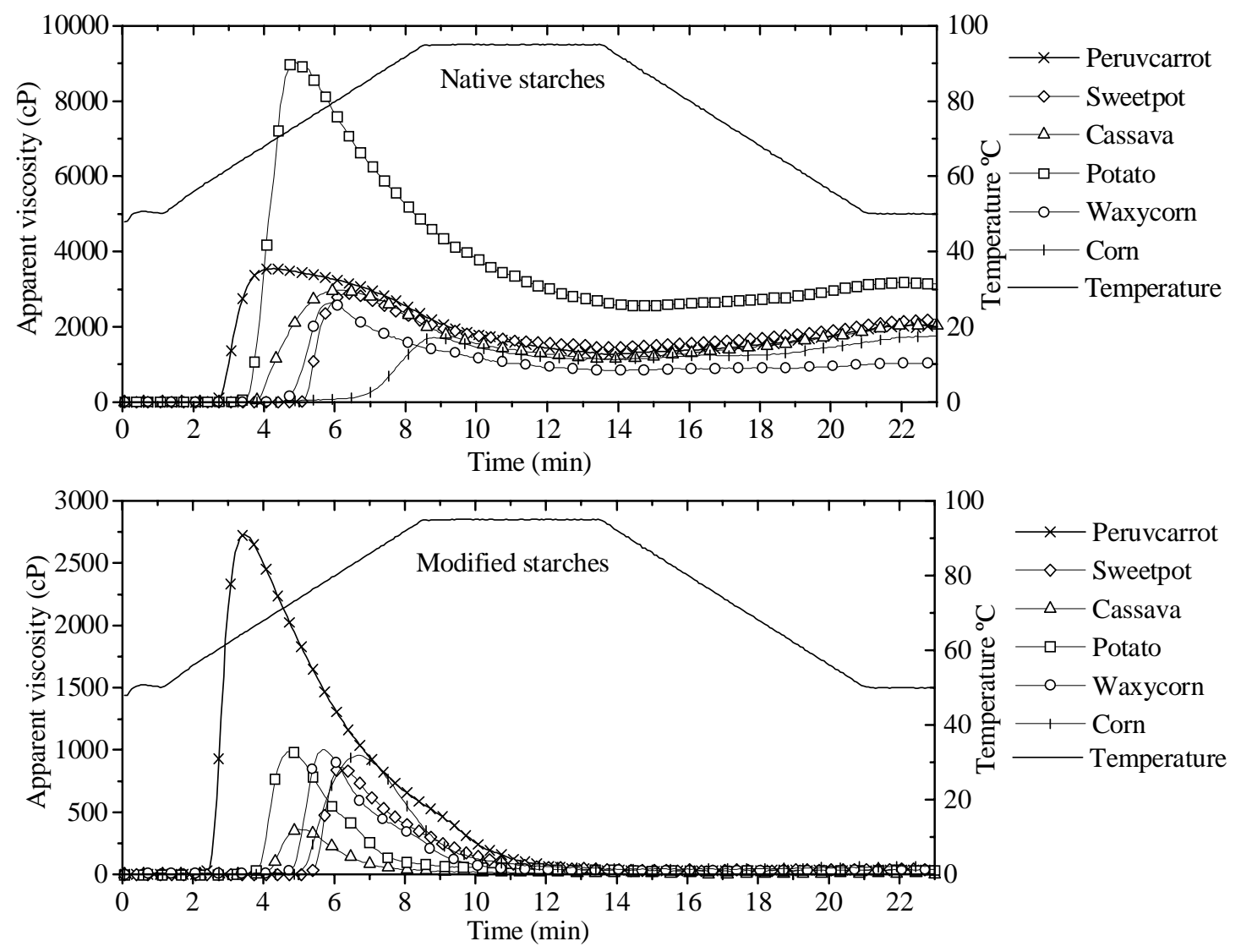

Figure 1 - Viscoamylograms of native and modified starches. 
The oxidative chemical modification resulted in pastes with low viscosities what can be explained by the lower molecular weight of starch macromolecules (Chung et al., 1999; Hebeish et al., 1989; Kuakpetoon and Wang, 2001; Morton and Solarek, 1984; Potze and Hiemstra, 1963).

The lower molecular weight of the macromolecules of cassava starch modified by the same chemical treatment using permanganate/lactic acid was showed by Demiate and Cereda (2000) who had analyzed the intrinsic viscosity. Although all modified samples presented lower viscosities, with high cooking instability, in the case of Peruvian carrot, it was possible to observe a relatively high viscosity peak, which suggested a different behavior of the tuberous starch when submitted to the considered chemical treatment.

Scores

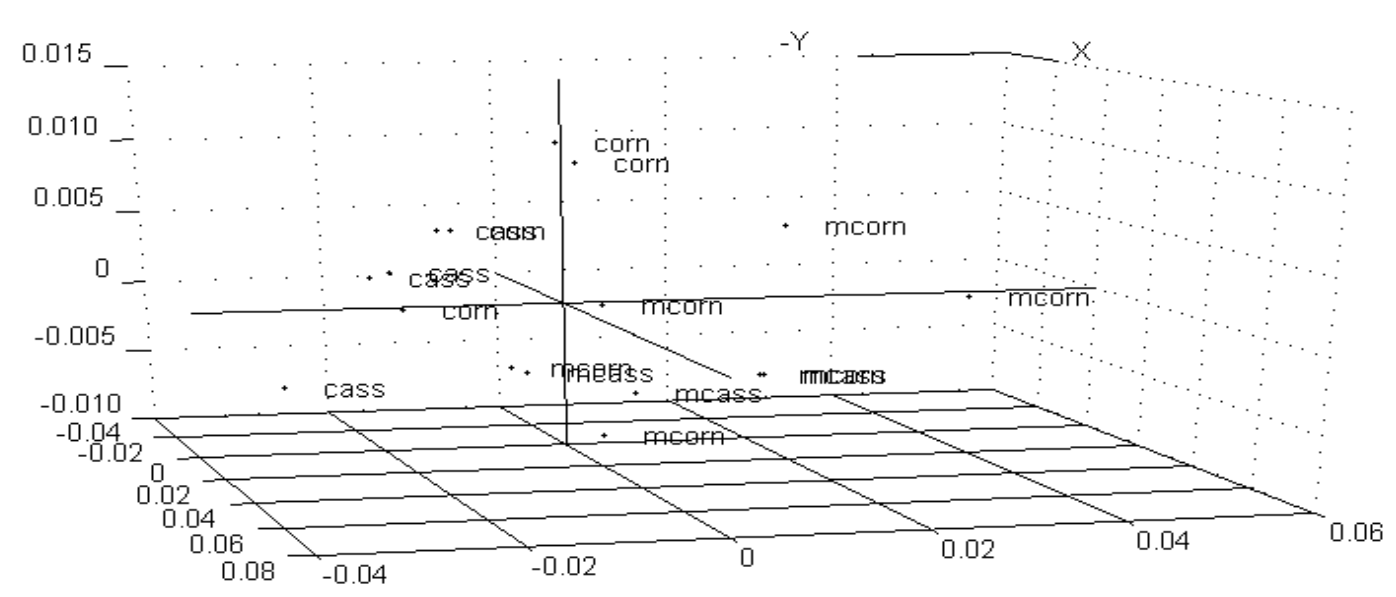

RESULT2, X-expl: $75 \%, 22 \%, 2 \%$

X-loadings

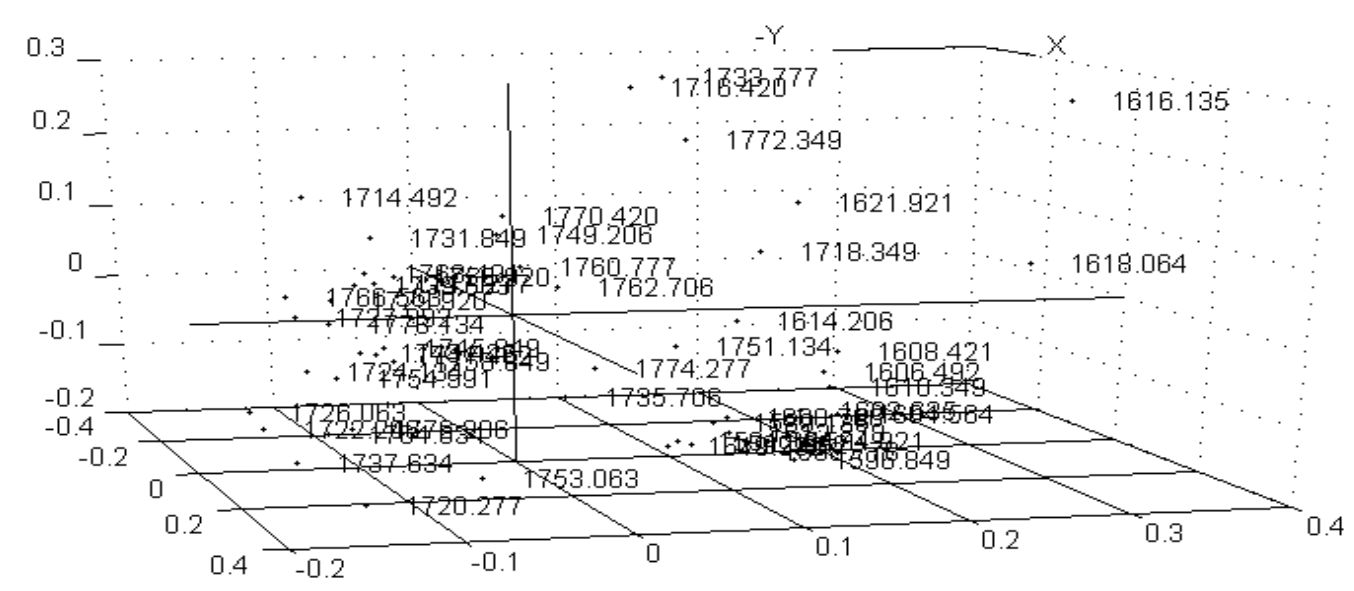

RESULT2, X-expl: 75\%,22\%,2\%

Figure 2 - Scores (above) and loadings of the three first principal components for modified and native corn and cassava starches. 


\section{Paste clarity}

The results showed that the clarity of the paste was related with the solubility of starch granules, because as more soluble was the sample, more transparent the paste. All modified starches produced translucent or transparent pastes, as shown in Table 3.

\section{Mid-infrared spectroscopy}

Analyzing the spectra obtained by mid-infrared spectroscopy, it was not possible to visualize any difference in the molecular starch structure. Although the samples were oven-dried before the infrared spectroscopic analyses, there were problems with moisture that interfered in the results. Using the principal component analysis (PCA), it was possible to classify the samples considering the spectral range from $1589-1620$ and $1714-1778 \mathrm{~cm}-1$. The scores and loadings of the three first principal components (explained variance of 99\%) are shown in Fig. 2, considering native and modified corn (corn/mcorn) and cassava (cass/mcass) starches.

The results showed a good separation from modified and native starches that could be associated with the presence of carboxyl groups in modified starches. Demiate et al. (2000) detected high carboxyl content in modified cassava starch samples after the same oxidative modification The spectral bands 1600 and $1730 \mathrm{~cm}^{-1}$ were characteristic of anionic and acid carboxyl, respectively.

\section{Expansion property}

The results obtained showed that the native starches had low expansion values (1.2 to 3.1 $\left.\mathrm{mL} . \mathrm{g}^{-1}\right)$, except the waxy corn starch $\left(8.5 \mathrm{~mL} \cdot \mathrm{g}^{-1}\right)$. After the oxidative treatment the expansion values increased, especially for waxy corn starch (19.4 mL.g $\mathrm{m}^{-1}$ ), but not for regular corn starch $\left(1.2 \mathrm{~mL} \cdot \mathrm{g}^{-1}\right)$. Waxy corn and cassava had higher expansion values when compared to other samples, and for this characteristic they are important in snacks production (HUANG, 2000).

\section{Syneresis}

Susceptibility to syneresis is an important property of starches, characterized by water leaking from pastes during cooling. In the first freeze-thaw cycle, it was observed that more water was freed from the modified samples, varying from 23 to $75 \%$ in relation to the initial weight; for the native samples, water liberation ranged from 0 to $60 \%$. Native waxy corn and cassava starches showed low susceptibility to syneresis when considering the two cycles. In the second cycle, the results indicated that almost all the samples lost more water.

The fragmentation of starch chains during the chemical treatment could be associated with the higher water liberation due to intensive molecular reassociation. Considering average values of the first and second freeze-thaw cycles, in case of native samples, the susceptibility to syneresis was: corn > potato $=$ sweet potato $>$ Peruvian carrot $>$ waxy corn $>$ cassava. For the modified starches, the susceptibility changed as follows: corn $>$ sweet potato $>$ cassava $>$ potato $>$ waxy corn $>$ Peruvian carrot.

Table 4 - Starch paste behavior during freeze-thaw cycles.

\begin{tabular}{|c|c|c|}
\hline \multirow{2}{*}{ Source } & \multicolumn{2}{|c|}{ \% liberated water } \\
\hline & $1^{\text {st }}$ cycle & $2^{\text {nd }}$ cycle \\
\hline \multicolumn{3}{|c|}{ Native starches } \\
\hline Peruvian carrot & 36 & 56 \\
\hline Cassava & 0 & 0 \\
\hline Corn & 60 & 74 \\
\hline Potato & 39 & 71 \\
\hline Sweet potato & 46 & 68 \\
\hline Waxy corn & 0 & 9 \\
\hline \multicolumn{3}{|c|}{ Modified starches } \\
\hline Peruvian carrot & 23 & 71 \\
\hline Cassava & 66 & 68 \\
\hline Corn & 75 & 72 \\
\hline Potato & 59 & 70 \\
\hline Sweet potato & 70 & 74 \\
\hline Waxy corn & 48 & 72 \\
\hline
\end{tabular}


Amylose content was related with the behavior of the native starch samples, what could be observed by comparing their order of susceptibility to syneresis with the data from Table 1. For the modified samples, there was influence of the amylose content but it seemed that there were other factors that interfered. This was especially clear for Peruvian carrot starch that was different from the others in the syneresis susceptibility as well as in the viscographic analysis.

\section{CONCLUSIONS}

The modified starches studied in this work presented different properties from the respective native, evidenced by higher susceptibility to syneresis, carboxyl content, reducing power and paste clarity, different solubility and swelling power behavior and RVA cooking pattern showing lower peak viscosity and higher cooking instability. All modified starches, except corn, presented higher expansion when baked, which was possibly associated with their amylopectin fraction. The expansion was inversely related with the amylose content of the starches. These modified properties were influenced by the presence of carboxyl groups as well as molecular weight changes. In the case of Peruvian carrot starch, there was some different behavior on RVA cooking pattern as well as on the susceptibility to syneresis. The $\mathrm{pH}$ of modified tuberous starches was always lower than that of the respective native starches, but in the case of the studied cereal starches (corn and waxy corn), the opposite situation occurred.

\section{ACKNOWLEDGEMENTS}

The authors are grateful to the Conselho Nacional de Desenvolvimento Científico e Tecnológico (CNPq) for financial support (Proc. 473799/01-4), the Centro de Raízes e Amidos Tropicais (CERAT/UNESP - Botucatu SP- FAPESP $\mathrm{n}^{\circ}$ 98/01649-9) for the infrared analyses and to ESALQ/USP (Piracicaba SP) for the RVA analyses and also to Corn Products Brasil for providing the waxy corn starch sample.

\section{RESUMO}

No presente trabalho alguns amidos tropicais foram modificados por tratamento oxidativo com permanganato de potássio e ácido lático. Amidos nativos e modificados foram avaliadas por espectroscopia na região do infravermelho médio, coloração diferencial, $\mathrm{pH}$, propriedade de expansão, poder de inchamento e solubilidade, claridade das pastas, susceptibilidade a sinérese, teor carboxilas e poder redutor. Todas as amostras modificadas adquiriram intensa coloração azul quando suspensas em azul de metileno, maiores valores de expansão (exceto o amido de milho), teor de carboxilas e poder redutor. A solubilidade dos grânulos dos amidos modificados foi muito alta a temperatura de $90^{\circ} \mathrm{C}$, não tendo sido possível medir o poder de inchamento. A análise viscográfica mostrou um decréscimo no pico de viscosidade e alta instabilidade ao cozimento. A análise dos componentes principais dos espectros de infravermelho médio permitiu a separação entre as amostras nativas e modificadas devido a presença de carboxilas. A expansão das amostras foi inversamente relacionada com os teores de amilose.

\section{REFERENCES}

Ali, S. Z. and Kempf, W. (1986), On the degradation of potato starch during acid modification and hypochlorite oxidation. Starch/Stärke, 38, 83-86.

Autio, K.; Suortti, T.; Hamunen, A. and Poutanen, K. (1996), Heat-induced structural changes of acidhydrolysed and hypochlorite-oxidized barley starches. Carbohydrate Polymers, 29, 155-161.

Boruch, M. (1985), Transformations of potato starch during oxidation with hypochlorite. Starch/Stärke, 37, 91-98.

Cereda, M. P.; Franco, C. M. L. and Daiuto, E. R. et al. (2001), Propriedades Gerais do Amido. Campinas : Fundação Cargill. v. 1. 224 Pp.

Chung, M. G.; Jeon, Y. S.; Lee, S. K.; Park, J. M. and Lim, B. S. (1999), Physicochemical properties of oxidized waxy maize starches with sodium hypochlorite. Korean Journal Food Science Technology, 30, 42-48.

Demiate, I. M. (1999), Desenvolvimento de fécula de mandioca auto-expansível por reação com permanganato de potássio e ácido lático. Ph.D. Thesis, Faculdade de Ciências Agronômicas, UNESP, Botucatu, Brazil. 
Demiate, I. M. and Cereda, M. P. (2000), Some physico-chemical characteristics of modified cassava starches presenting baking property. Energia na Agricultura, 15, 36-46.

Demiate, I. M.; Dupuy, N.; Huvenne, J. P.; Cereda, M. P. and Wosiacki, G. (2000), Relationship between baking behavior of modified cassava starches and starch chemical structure determined by FTIR spectroscopy. Carbohydrate Polymers, 42, 149-158.

Demiate, I. M.; Konkel, F. E. and Pedroso, R. A. (2001), Avaliação da qualidade de amostras comerciais de doce de leite pastoso - composição. Ciência e Tecnologia de Alimentos, 21, 108-114.

Dendy, D. A.V. and Dobraszczyk, B. J. (2001), Cereals and Cereals Products: Chemistry and Technology, Gaithersburg: AN Aspen Publishers, p. 409.

Dolmatova, L., Ruckebush, C.; Dupuy, N.; Huvenne, J. P. and Legrand, P. (1998), Identification of modified starches using infrared spectroscopy and artificial neural network processing. Society for Applied Spectroscopy, 52, 329-338.

Dupuy, N.; Wojciechowski, C.; Ta, C. D.; Huvenne, J. P. and Legrand, P. (1997), Mid- infrared spectroscopy and chemometrics on corn starch classification. Journal of Molecular Structure, 410-411, 551- 554.

Dupuy, N. (1993) Analyse quantitative par spectrométrie moyen infrarouge par transformée de Fourier, mise au point des protocoles transposables en millieu industriel, Lille, Thèse de doctorat Université du Droit et de la Santé de Lille. 120 pp.

Forssell, P; Hamunen, A.; Autio, K.; Suortti, T. and Poutanen, K. (1995), Hypochlorite oxidation of barley and potato starch. Starch/Stärke, 10, 371-377.

Galliard, T. and Bowler, P. (1987), Morphology and composition of starch. In: T. Galliard. Starch Properties and Potential, Chichester : Wiley. pp. 55-78.

Garcia, V. (1996), Transitions thermiques de l'amidon de manioc en millieux peu hydratés. Paris. Thèse de doctorat - Intitut National Agronomique de Paris Grignon.

Hashim, D. B. M.; Moorthy, S. N.; Mitchell, J. R.; Hill, S. E., Linfoot, K. J. and Blanshard, J. M. V. (1992), The effect of low levels of antioxidants on the sweeling and solubility of cassava starch. Starch/ Starke, 44, 471-475.

Hebeish, A.; El-Thalouth, I. A.; Refai, R. and Ragheb, A. (1989), Synthesis and characterization of hypochlorite oxidized starches. Starch/ Stärke, 41, 293-298.

Hoover, R. (2001), Composition, molecular structure, and physicochemical properties of tuber and root starches: a review. Carbohydrate Polymers, 45, 253-267.

Huang, D. P. (2000), New perspectives on starch and starch derivatives for snack applications. National Starch and chemical company. Disp. in: www.foodstarch.com/products_services/pdfs/newpers p.pdf. Acess in: 15 jul. 2002.
International Starch Institute. Determination of reductive power in starch. Disp. in: http://home3.inet.tele.dk/starch/isi/methods/

35rcu.htm. Access in: 22 jul. 2001.

Kuakpetoon, D. and Wang, Y. J. (2001), Characterization of Different Starches Oxidized by Hypochlorite. Starch/ Stärke, 53, 211-218.

Leach, H. W.; McCowen, D. L. and Schoch, T. J. I. (1959), Swelling and solubility patterns of various starches. Structure of starch granules. Cereal Chemistry, 38, 34-46.

Leonel, M. and Cereda, M. P. (2002), Caracterização físico-química de algumas tuberosas amiláceas. Ciência e Tecnologia de Alimentos, 22, 65-69.

Lii, C. Y.; Shao, Y. Y. and Tseng, K. H. (1995), Gelation mechanism and rheological properties of rice starch. Cereal Chemistry, 72, 393-400.

Mestres, C. and Rouau, X. (1997), Influence of natural fermentation and drying conditions on the physicochemical characteristics of cassava starch. $J$. Science Food Agric., 74, 147-155.

Moorthy, S. N. (1994), Tuber Crop Starches. Thiruvananthapuram : Central Tuber Crops Research Institute. 40 pp. (Tech. Bulletin Series, 18).

Morton, M. W. and Solarek, D. (1984), Starch derivatives: production and uses. Starch Chemistry and Technology. 2. ed. New York : Academic Press. pp. 311-366.

Parovuori, P.; Hamunen, A.; Forssell, P.; Autio, K. and Poutanen, K. (1995), Oxidation of potato starch by hydrogen peroxide. Starch/Stärke, 47, 19-23.

Paterson, L. A.; Hashim, D. B. M.; Hill, S. E.; Mitchell, J. R. and Blanshard, J. M. V. (1994), The effect of low levels of sulphite on the swelling and solubility of starches. Starch/Starke, 46, 288-291.

Potze, J. and Hiemstra, P. (1963), The influence of the reaction conditions upon the oxidation of potato starch with hypochlorite. Starch/ Stärke, 15, 217-225.

Silva, G. O.; Takizawa, F. F. and Demiate, I. M. (2002), Amidos tropicais - Extração de fécula e caracterização físico-química da batata doce. In: Paper presented at XVIII Congresso Brasileiro de Ciência e Tecnologia de Alimentos, 4- $7^{\text {th }}$ August, Porto Alegre RS, Brasil.

Smith, P. S. (1982), Starch derivatives and their use in food. In: Lineback, D. R. and Inglett, G. E. Food Carbohydrates. Westport : AVI Publishing Company. pp. 237-269.

Tester, R. F. and Morrison, W. R. (1990), Swelling and gelatinization of cereal starches I.Effects of amylopectin, amylose and lipids. Cereal Chemistry, 67, 551-557.

The Unscrambler (1997), Software for multivariate data analysis, ver. 6, Trondheim : CAMO (Manual of instructions).

Thomas, D. J. and Atwell, W. A. (1999), Starches, Minnesota : Egan Press. pp. 91. 
Wang, Y. J. and Wang, L. (2003) Physicochemical properties of common and waxy corn starches oxidized by different levels of sodium hypochlorite. Carbohydrate Polymers, 52, 207-217.

Zheng, G. H. and Sosulski, F. W. (1998), Determination of water separation from cooked starch and flour pastes after refrigeration and freeze-thaw. Journal of Food Science, 63, 134-139.

Received: December 09, 2002; Revised: September 11, 2003; Accepted: May 10, 2004. 